\title{
Gender Differences in Child Malnutrition in Ethiopia: Evidence from Three Decomposition Techniques
}

\author{
Meijuan Wang ${ }^{1}$, Denis Nadolnyak ${ }^{1,{ }^{*}} \&$ Valentina Hartarska ${ }^{1}$ \\ ${ }^{1}$ Department of Agricultural Economics and Rural Sociology, Auburn University, Auburn, \\ Alabama, USA \\ *Department of Agricultural Economics and Rural Sociology, Auburn University, 310 Comer \\ Hall, Auburn, Alabama, USA. Tel: 1-334-559-0362. E-mail: nadolda@auburn.edu
}

Received: July 28, 2021 Accepted: August 10, $2021 \quad$ Published: September 24, 2021

doi: 10.5296/rae.v13i3.19056 URL: https://doi.org/10.5296/rae.v13i3.19056

\begin{abstract}
Ethiopia has one of the highest under-five child mortality rate in the world, which is higher for boys than for girls. Malnutrition is a major contributing factor to child mortality and that is why we assess the differences in child malnutrition status of boys and girls. Specifically, we study the extent to which the gender differences in malnutrition are associated with observable factors and socio-economic characteristics and to what extent these differences are unexplained and attributable to factors such as latent parental preferences, societal biases, and other unobservable factors. We use data from the Ethiopia Demographic and Health Survey and evaluate three anthropometric status measures - wasting, stunting, and being underweight. We utilize a reduced-form demand for nutrition framework and several decomposition techniques: Oaxaca-Blinder decomposition for non-linear models, Machado-Mata quantile decomposition, and the recentered influence function. The results indicate that measurable socioeconomic and locational characteristics have significant and plausible associations with malnutrition by gender. We also find that $3 \%$ to $4 \%$ of the difference in the anthropometric status may be attributable to unobservable factors that may include implicit parental preferences. This approach is useful in evaluating gender differences in other human capital development outcomes such as health and education, as well as those in malnutrition.
\end{abstract}

Keywords: malnutrition, Ethiopia, gender differences, non-linear Oaxaca-Blinder decomposition, Machado-Mata quantile decomposition, re-centered influence function decomposition

JEL codes: O10, O15, I15 


\section{Introduction}

Ethiopia is a country with historically very high rates of child malnutrition, although these rates have been declining (Lintelo and Lakshman, 2015; Headey, Hoddinott, and Park, 2017). Estimates show that close to half of the children under the age of five (48 percent or 6.3 million) were undernourished in 2014 (FAO, 2020). Poverty and a lack of educational opportunities affect households' ability to feed their children and the country has one of the lowest ratings in the Human Development Index in the world (0.442). We analyze the differences in malnutrition rates between boys and girls under the age of five in Ethiopia and evaluate whether endowments, unexplained factors attributable to parental preferences, societal biases, and other unobservable factors, or both (endowment and preferences) drive these differences.

The literature on child malnutrition is extensive and focuses largely on differences in nutritional outcomes with respect to income, child age, socioeconomic characteristics, and rural-urban and geographic locations (May and Timæus, 2014; Mussa, 2015; Pulok, Sabah and Enemark, 2016; Wagstaff and Watanabe, 2003; Smith, Ruel and Ndiaye, 2005 ). Our work relates to the more limited literature on gender differences in malnutrition status. These studies show that, in general, while girls have worse nutritional outcomes than boys in India, the opposite findings emerge for African countries (Bork \& Diallo, 2017; Jayachandran \& Kuziemko, 2011; Jayachandran \& Pande, 2017; Sahn and Stifel, 2002; Klasen, 1996; Sahn \& Stifel, 2002; Svedberg, 1990; Wamani, Åstrøm, Peterson, Tumwine, \& Tylleskär, 2007).

Nutritional inequality between boys and girls may be driven by parental preferences motivated by concerns for equity, efficiency, and possibly societal and implicit parental biases (Berhman, 1988). The equity concern reflects the desire of parents to ensure that children are equally well off. If nutritional needs differ by gender, then the observed gender differences may be due to equity bias. The efficiency concern relates to the differences in returns on investment in a child's health and well-being. If the returns are different for boys and girls, gender preference are efficiency driven (Oyekale, 2014). Sahn and Stifel (2002), for example, find that in Africa in the 1990s there was a considerable diversity in gender norms, most favoring men in terms of acquisition and inheritance of property using a representive sample of countries (Sahn and Stifel, 2002).(Note 1) The evidence also shows differences in investing food aid in boys and girls, with girls' nutrition improvements related to free distribution of food, while boys benefiting from food-for-work (Quisumbing, 2003). Evidence from adult consumption in Ethiopia also reflects a gender bias as parents tend to invest more in unwanted boys' early health (through breastfeeding and vaccination) relative to unwanted girls (Koohi-kamali, 2008; Reshid, 2017). Yet, these results are in contrast to the observed under-five mortality rates for boys relative to girls.

Indeed, child mortality under the age of five in Ethiopia is among the highest in the world and is higher for boys than for girls. The World Bank reports mortality rates per 1,000 for age under five of 90.5 for boys and 74.9 for girls in 2010 with gender difference remaining even though rates for both genders had fallen in 2015 and 2018 (The World Bank Gender Data, 2020). (Note 2) Child malnutrition is a particularly serious long-term crisis estimated to cause $45 \%$ of all childhood deaths (Black et al., 2013). The main causes of child deaths in Ethiopia are diarrhea, 
malaria, and pneumonia, all related to malnutrition because better nutrition improves ability to survive these diseases (Ethiopian DHS, 2011). Thus, it is important to gain an understanding of the nutritional inequalities that may exist between boys and girls during their first five years of life, as well as to what extent potential differences are due to biology, socio-economic factors known to affect malnutrition, and possibly latent parental preferences, societal biases, and other unobservable factors.

Our approach utilizes a reduced-form demand for nutrition equation and incorporates specific factors that affect child malnutrition in Ethiopia. For example, in rural areas, the volatility in food prices in 2008 and 2010-2011 caused welfare losses for households (Bellemare, Barrett, and Just, 2013). Rural hunger is an important concern because about 80 percent of the labor force in Ethiopia is located in rural areas. With Ethiopia's rapid population increase, the per capita farmland has decreased and soil fertility declined with intensive subsistence farming further affecting the farmers' ability to feed their families (Kebede, 2005). Ethiopia's economy relies greatly on agriculture that requires a labor force with greater physical strength, suggesting that the expected return on boys may be higher than the return on girls but this does not seem to be reflected in boys' nutrition status. Studies have found that, in Ethiopia, the parents' income, socioeconomic factors, and education along with the duration of breastfeeding and the age of children affect their health (Kebede, 2005; Atsbeha, Nayga and Rickertsen, 2015; Zewdie and Abebaw, 2013)

Our methodological approach is close to recent studies applying regression decomposition techniques to understand changes in nutritional outcomes over time (Headey, 2014; Headey, Hoddinott, \& Park, 2017), between rural and urban areas (Hirvonen, 2016), and household wealth levels (Mohammed et al., 2019). Methodologically, it is closest to two papers using decomposition techniques to evaluate the differences in nutritional outcomes by gender in rural China (Ren, Rammohan, \& Wu, 2014) and in the US (Taber et al., 2016).

Our contribution to the literature is as follows. While differences in observable anthropometric status between boys and girls are well documented, there has been little work evaluating the observable or unobservable factors that may drive these differences, particularly whether parents' explicit and implicit preferences for boys or girls are associated with children's malnutrition status. Thus, our contribution is to explicitly test if child malnutrition differs by gender in Ethiopia and if these differences are attributable to endowments or unexplained factors such as implicit parental preferences, societal biases, and other unobservable factors using data from the 2011 Ethiopia DHS. To achieve this objective, we apply several decomposition techniques used in health and labor economics. We first apply the OaxacaBlinder decomposition for non-linear models for the Z-scores defining children as malnourished according to three measures of nutrition status (Sinning, Hahn and Bauer 2008; Daymont and Andrisani, 1984). We then use the extension by Machado and Mata (2005) to gain insights into differences in gender malnutrition among different quantiles of the dependent variable. As an additional robustness check, we evaluate the individual contribution of each regressor to the malnutrition of boys and girls by quantiles using the recentered influence function (RIF) approach (Firpo et al., 2007 and 2009). Our findings show that girls recorded in the survey have lower malnutrition status than boys and that a small percentage of that 
malnutrition may be attributable to unobservable factors that may be attributable to implicit parental preferences or societal biases.

The reminder of this paper is organized as follows: In section 2, we describe our methods and define the malnutrition measures used in this study. In section 3, we introduce the data and provide descriptive statistics. Section 4 presents the results and discusses policy implications. The last section concludes.

\section{Empirical Model}

We start by outlining the decomposition method to estimate the difference between genders in terms of the predicted probability of being malnourished. Following Blinder (1973) and Oaxaca (1973), there are separate models for girls and for boys:

$$
\begin{aligned}
& Y_{b}=\boldsymbol{X}_{b} \beta_{b}+e_{b}, \\
& Y_{g}=\boldsymbol{X}_{g} \beta_{g}+e_{g},
\end{aligned}
$$

in which $\mathrm{Y}$ is the outcome variable, $b$ and $g$ denotes boys and girls, and $\mathrm{X}$ is a vector of control variables. The overall outcome difference is decomposed as

$$
\overline{Y_{b}}-\overline{Y_{g}}=\left(\boldsymbol{X}_{b}-\boldsymbol{X}_{g}\right) \beta_{b}+\boldsymbol{X}_{g}\left(\beta_{b}-\beta_{g}\right)
$$

where the left-hand side is the raw gender difference in average malnutrition. The right-hand side consists of two terms: the first is the difference due to observable characteristics while the second shows the coefficient difference sometimes referred to as "unexplained". Changing the reference group, an alternative expression is:

$$
\overline{Y_{g}}-\overline{Y_{b}}=\left(\boldsymbol{X}_{g}-\boldsymbol{X}_{b}\right) \beta_{g}+\boldsymbol{X}_{b}\left(\beta_{g}-\beta_{b}\right)
$$

However, the decomposition format of (3) and (4) is not appropriate when the outcome variable, in our case the three classical measures of malnutrition, is not a continuous variable. To adjust, the decomposition is rewritten in a nonlinear form following Sinning, Hahn and Bauer (2008):

$$
\begin{aligned}
& \Delta_{b}^{N L}=\left\{E_{\beta_{b}}\left(Y_{b} \mid \boldsymbol{X}_{b}\right)-E_{\beta_{b}}\left(Y_{g} \mid \boldsymbol{X}_{g}\right)\right\}+\left\{E_{\beta_{b}}\left(Y_{g} \mid \boldsymbol{X}_{g}\right)-E_{\beta_{g}}\left(Y_{g} \mid \boldsymbol{X}_{g}\right)\right\}, \\
& \Delta_{g}^{N L}=\left\{E_{\beta_{g}}\left(Y_{b} \mid \boldsymbol{X}_{b}\right)-E_{\beta_{g}}\left(Y_{g} \mid \boldsymbol{X}_{g}\right)\right\}+\left\{E_{\beta_{b}}\left(Y_{b} \mid \boldsymbol{X}_{b}\right)-E_{\beta_{g}}\left(Y_{b} \mid \boldsymbol{X}_{b}\right)\right\} .
\end{aligned}
$$

As proposed by Daymont and Andrisani (1984), we extend our decomposition to three components:

$$
\bar{Y}_{b}-\bar{Y}_{g}=\left(\boldsymbol{X}_{b}-\boldsymbol{X}_{g}\right) \beta_{g}+\boldsymbol{X}_{g}\left(\beta_{b}-\beta_{g}\right)+\left(\boldsymbol{X}_{b}-\boldsymbol{X}_{g}\right)\left(\beta_{b}-\beta_{g}\right)=E+C+C E
$$

in which $\mathrm{E}$ is the part of a raw differential that is due to the difference in endowments, $\mathrm{C}$ displays the difference in coefficients, and $\mathrm{CE}$ represents the interaction effect between $\mathrm{E}$ and 
C. In the nonlinear case, the components are:

$$
\begin{aligned}
& E=\left\{E_{\beta_{g}}\left(Y_{b} \mid \boldsymbol{X}_{b}\right)-E_{\beta_{g}}\left(Y_{g} \mid \boldsymbol{X}_{g}\right)\right\} \\
& C=\left\{E_{\beta_{b}}\left(Y_{g} \mid \boldsymbol{X}_{g}\right)-E_{\beta_{g}}\left(Y_{g} \mid \boldsymbol{X}_{g}\right)\right\} \\
& \quad C E=\left\{E_{\beta_{b}}\left(Y_{g} \mid \boldsymbol{X}_{g}\right)-E_{\beta_{g}}\left(Y_{b} \mid \boldsymbol{X}_{b}\right)\right\}+\left\{E_{\beta_{b}}\left(Y_{g} \mid \boldsymbol{X}_{g}\right)-E_{\beta_{g}}\left(Y_{g} \mid \boldsymbol{X}_{g}\right)\right\}
\end{aligned}
$$

In the empirical analysis, the first step involves estimating two separate regressions for boys and girls. Then, the conditional $Y$ value is predicted for both boys and girls by using the other group's coefficients. The main interest is in the coefficient difference (part C) that is also called the "unexplained" or "structural" difference" that reflects the potential gender inequality in child nutrition.

Next, we examine whether a girl is likely to be more malnourished if she receives the same treatment as a boy. For that, we compute the difference as $C=\widehat{\beta_{b}} X_{g}-\widehat{\beta_{g}} X_{g}=\operatorname{Pr}^{g \mid b}-\operatorname{Pr}^{g}$ if the response variable is binary and $C=Z^{g \mid b}-Z^{g}$ if the response variable is continuous (Zscore).

We offer two further estimations to check the robustness of our results by investigating in more detail how malnutrition may vary within various quantiles. This is especially important because we suspect that the continuous measures of malnutrition likely vary by quantiles. For that purpose, we use the Machado and Mata (2005) approach that decomposes the dependent variable with a quantile regression. With this approach, we can also decompose the gender gap in (mal)nutrition into two parts. The first element is the contribution of the difference in observable characteristics in the $X$ variables and the second is the unexplained difference in coefficients that may reflect the parents' or other biases.

The procedure follows several steps. First, we generate a random sample $e_{1}, e_{2}, \ldots e_{b}$ with uniform distribution $E[0,1]$. Second, we use data for boys and run a $\tau$ quantile regression at $\tau=e_{i}$ to get $b$ estimates for the quantile coefficients $\hat{\beta}_{\tau}^{b}$. Third, we generate a $b$ size random sample $S^{g}$ from the girls' data with replacement. Fourth, we construct a counterfactual distribution with the coefficients from step two and the sample from step three, which is written as $y_{\tau}^{c}=S^{g} \hat{\beta}_{\tau}^{b}$. Then the aggregate decomposition at each quantile is

$$
y_{\tau}^{b}-y_{\tau}^{g}=\left(y_{\tau}^{b}-y_{\tau}^{c}\right)+\left(y_{\tau}^{c}-y_{\tau}^{g}\right)
$$

in which the first term on the right-hand side denotes the effect of the covariates and the second term denotes the effect of the coefficients.

The Machado and Mata's (2005) approach is similar to that of DiNardo et al. (1996) in capturing the contribution of individual covariates. DiNardo et al. (1996) use a reweighting procedure to construct a counterfactual distribution of the dependent variable (e.g., wage, Zscore). This approach is the best at capturing the individual contributions of the coefficients 
when the covariates are dummy variables. Firpo et al. $(2007,2009)$ propose a further improvement, which we use here, that is based on the RIF (re-centered influence function). The first step in the RIF is to construct the counterfactual distribution of the nutrition measure $(y)$. Then, for the $\tau$ th quantile of the distribution $q_{\tau}$, the RIF is

$$
\operatorname{RIF}\left(y ; q_{\tau}, F_{Y}\right)=q_{\tau}+\frac{\tau-1\left\{y \leq q_{\tau}\right\}}{f_{Y}\left(q_{\tau}\right)}
$$

in which $\frac{\tau-1\left\{y \leq q_{\tau}\right\}}{f_{Y}\left(q_{\tau}\right)}$ is the influence function, and $f_{Y}\left(q_{\tau}\right)$ is the density of $y$ evaluated at $q_{\tau}$. As the expected value of the influence function is zero, the expectation of the RIF is:

$$
\mathrm{E}\left[R I F\left(y ; v\left(F_{Y}\right) \mid X\right]=X_{i}^{\prime} \beta\right.
$$

Combining the RIF model with the counterfactual measure of nutrition in the decomposition equation can be written as:

$$
\begin{aligned}
\mathrm{v}\left(F_{Y_{b}}\right)-\mathrm{v}\left(F_{Y_{g}}\right) & =\left(\bar{X}_{b} \beta_{b}^{v}-\bar{X}_{b} \beta_{c}^{v}\right)+\left(\bar{X}_{b} \beta_{c}^{v}-\bar{X}_{g} \beta_{g}^{v}\right) \\
& =\bar{X}_{b}\left(\beta_{b}^{v}-\beta_{c}^{v}\right)+\left(\bar{X}_{b}-\bar{X}_{g}\right) \beta_{g}^{v}+R_{0}
\end{aligned}
$$

The $\mathrm{v}\left(F_{Y}\right)$ is the distributional statistic of interest, and $R_{0}=\bar{X}_{b}\left(\beta_{c}^{v}-\beta_{g}^{v}\right)$ represents the approximate error. The explained part of the traditional Blinder-Oaxaca decomposition is called the composition effect, while the unexplained part is called the structural effect. Parallel to the classical decomposition in equation (4), the first part of (12) reflects the difference in the characteristics and the second part shows how the characteristics are "valued" by the parents" biases, that is, it serves as a measure for discrimination.

\subsection{Measures of Malnutrition}

The most common measures of child malnutrition, also known as anthropometric status, are wasting, stunting, and being underweight (World Food Programme and Center for Disease Control and Prevention, 2005). These categories are measures based on weight-for-height (WHZ, a measure of waisting), height-for-age (HAZ, a measure of stunting), and weight-forage (WAZ, underweight), and are the standards used in most studies on child malnutrition (Block and Webb, 2009; Salvucci, 2015; Lazzaroni and Wagner, 2016). The literature uses the $\mathrm{Z}$-scores as the relevant measure, which is calculated with the following formula:

$$
\text { Zscore }=\frac{\text { observed value-median value of the reference population }}{\text { standard deviation value of reference population }}
$$

This is a normalized health index that is useful for comparing an individual to a reference group of children of the same gender at the same age. Children with a Z-score two standard deviations (-2SD) below the reference population are considered moderately malnourished. (Note 3) Given that the methods we use permit both categorical and continuous values to be used as the dependent variables, we first describe the measures of malnutrition with three categorical 
variables. Wasting, Stunting, and Underweight equal to one if the corresponding Z-score is less than -2 .

Wasting is a short-term indicator for health and captures possible malnutrition in the period immediately preceding the survey. It is often associated with acute starvation or severe disease. It may also be the result of a chronically unfavorable condition. For example, weight loss could occur from diarrhea. Stunting is an indicator of chronic malnutrition or a lack of adequate nutrition over a long period. It reflects the failure to reach potential linear growth because of suboptimal health or nutritional conditions. This measure is not sensitive to short-term dietary changes. High levels of stunting are associated with poor socioeconomic conditions and the increased risk of frequent and early exposure to adverse conditions such as illness or inappropriate feeding practices. Being Underweight reflects body mass relative to chronological age and captures both short- and long-term effects of malnutrition. It does not work well in distinguishing between thin, tall children and short, lower weight children, but it is worth analyzing when there is less wasting or stunting information.

We start with estimating a logit model with the dependent variables equal to one if the child is malnourished (less than 2 SD from the mean) and zero otherwise. We also use OLS with continuous Z-scores, and compute the standard Blinder-Oaxaca type decomposition.

\section{Data}

We use household survey data from the 2011 Ethiopia Demographic and Health Survey (DHS). (Note 4) The survey was conducted in 11 regions and contains data for 9,450 children. As 80 percent of the labor force in Ethiopia is in the agricultural sector, weather plays an important role in rural areas where droughts are especially damaging and in 2011 there was a drought (Figure 1). Following Seleshi and Zanke (2004), to control for the effect of weather, we created a dummy variable that indicated whether a household lived in an area affected by drought during the year of data collection.

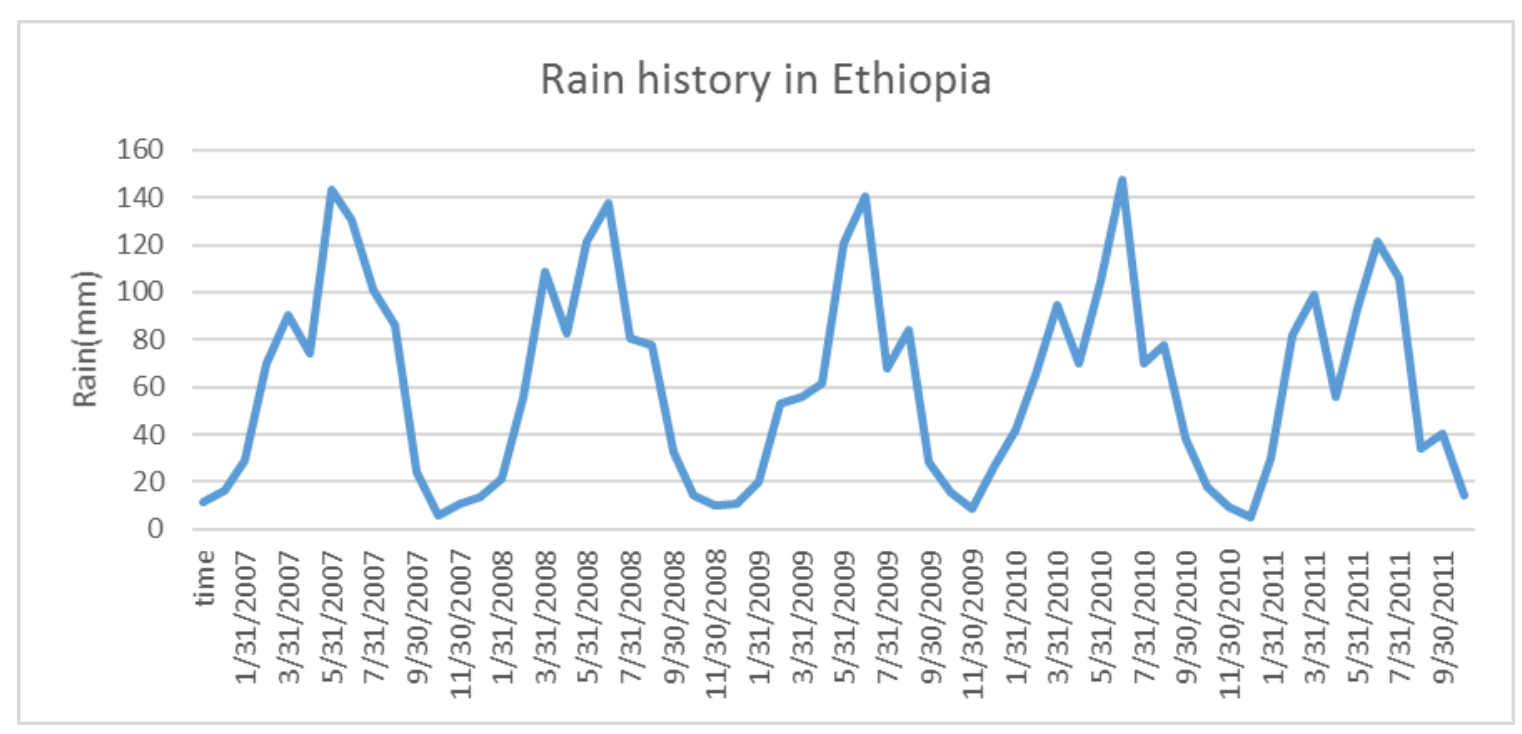

Figure 1. Temperature and Rain History in Ethiopia, Five Years before the Survey 
Figure 2 shows the distribution of the Z-scores for stunting, wasting, and being underweight. It shows that nearly one half of the children are (moderately) stunted. The data further show that for wasting, the larger part of the distribution of the boys' Z-scores falls below -2 (the red vertical line) compared to girls. The difference is less pronounced in the distribution of stunting that illustrates that boys are more vulnerable but to a much lower degree. However, visual inspection of the distributional differences by gender of the underweight category shows differences closer to those observed in wasting than to that in stunting indicating that more boys than girls are underweight.

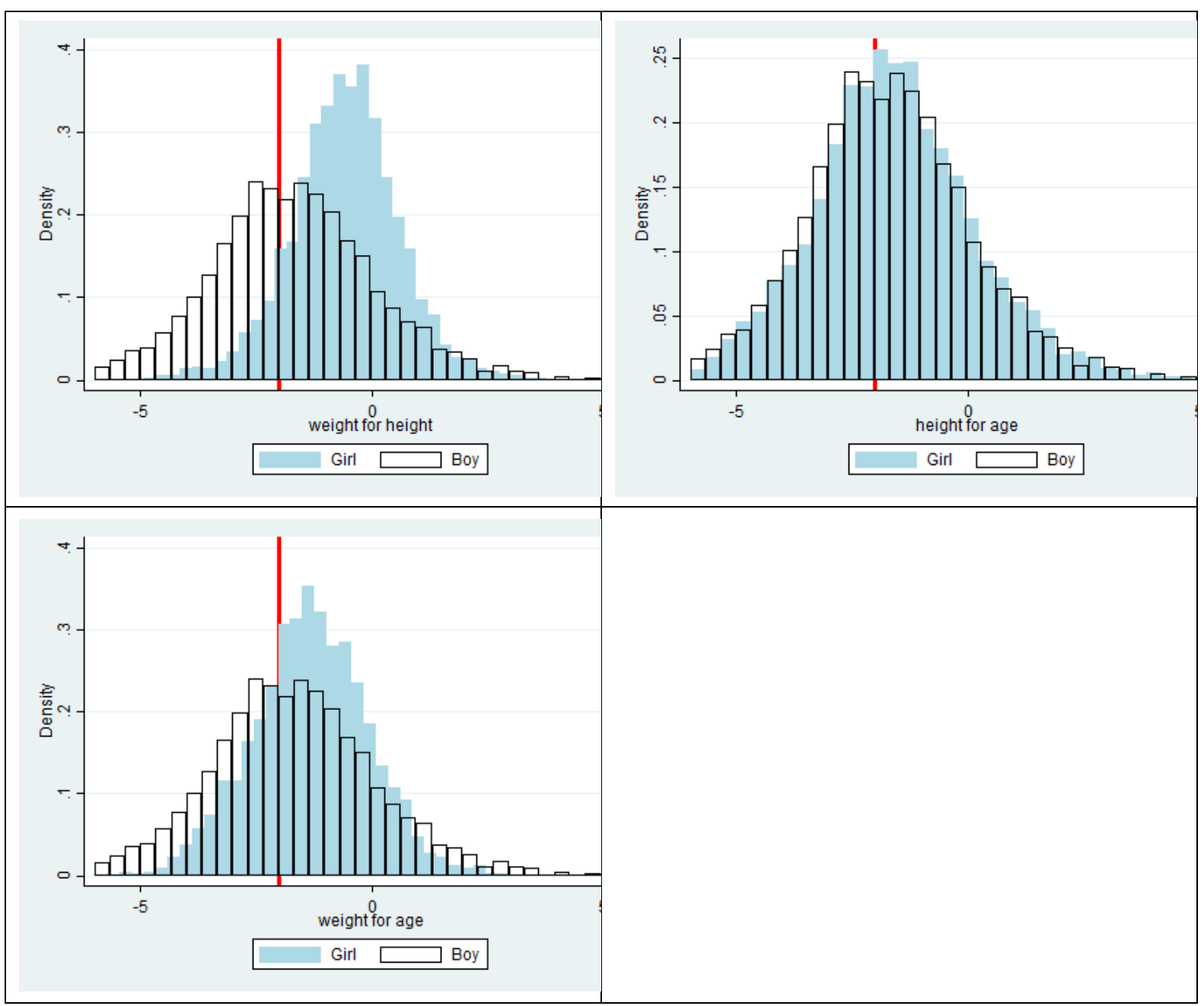

Figure 2. Distribution of Z-scores of Stunting (Height-for-Age), Underweight (Weight-forAge) and Wasting (Weight-for-Height)

Table 1 shows the percentages of boys and girls that fall within the moderately malnourished categories (Z-scores below -2). For most age categories of stunting and underweight, all indicators show that boys were more malnourished relative to girls. The differentials of all 
measures decrease in value as children get older, consistent with previous work (Black et al., 2013). We also consider the proportion of boys and girls in the sample (the first column in Table 1). While among children younger than 12 months and ages three to four girls represent 50 percent, at ages one to three girls represent 49 percent of all children, and at ages four to five they represent 47 percent. These declining proportions may simply be a sampling feature. Above the age of 5, the proportion of girls drops further to 44 percent, which may be a result of undercounting of girls or reflect girls' survival. (Note 5) The latter may be the case because a larger proportion of boys are wasted and stunted as well as underweight than girls, but fewer girls than boys are part of the sample by the age of five. When the shares of boys and girls are the same at 50 percent at ages three and four, the stunting (long term malnutrition measure) level of girls is equal to that of boys but slightly more girls are underweight (combination of malnutrition measure). When the proportion of girls drops to 47 percent after age four, this group of (surviving) girls is better nourished than the surviving boys who represent 53 percent of all children. In the absence of more information on whether girls are more or less likely to survive, other than the observed proportions, it is hard to interpret the raw data.

Table 1. Malnutrition of Boys and Girls by Age

\begin{tabular}{llllllll}
\hline \multirow{2}{*}{ Age } & $\begin{array}{l}\text { percent } \\
\text { girls }\end{array}$ & \multicolumn{2}{l}{$\begin{array}{l}\text { Wasting } \\
\text { (weight for height) }\end{array}$} & \multicolumn{2}{l}{$\begin{array}{l}\text { Stunting percent }{ }^{2} \\
\text { (height for age) }\end{array}$} & \multicolumn{2}{l}{$\begin{array}{l}\text { Underweight } \\
\text { (weight for age) }\end{array}$} \\
\cline { 2 - 8 } & & Boys & Girls & Boys & Girls & Boys & Girls \\
\hline Birth to 1 year & 50 & 19 & 15 & 15 & 12 & 19 & 13 \\
$1-2$ & 49 & 19 & 13 & 49 & 39 & 36 & 28 \\
$2-3$ & 49 & 11 & 8 & 56 & 55 & 39 & 35 \\
$3-4$ & 50 & 9 & 7 & 53 & 53 & 33 & 34 \\
$4-5$ & 47 & 9 & 8 & 47 & 45 & 33 & 31 \\
\hline
\end{tabular}

${ }^{1}$ wasting measures short-term malnutrition effect

${ }^{2}$ stunting measures long-term malnutrition effect

${ }^{3}$ underweight measures a combination of long- and short-term malnutrition effect

Some idea about explicit parental gender bias may come from the answer to the question of what is the ideal number of girls in a family. (Note 6) First, only 12 percent of the responding parents (typically the mothers) indicated that they did not have a gender bias and 3 percent chose the other category. (Note 7) Unsurprisingly, 13 percent of parents did not want girls at all, and 8 percent chose just one girl. (Note 8) Additionally, 30 percent stated that two girls was the ideal number and 14 percent chose three girls, while 19 percent chose more than three girls. With a woman giving birth on average to 4.8 children in Ethiopia, over a third of parents preferred more girls $(>3)$ and a third preferred no girls or one girl, so responding parents do not seem to express an explicit bias for boys or girls. (Note 9) Inside the dominant family size that consists of five or six members, girls are in the slight majority (50.5 percent) over boys, while in bigger families (more than six members) and in smaller families (less than five), boys are the majority at 52 percent and 51 percent respectively. (Note 10) A simplistic interpretation of explicit statements for preferences of a child's gender could mask significant variations and parents' biases that likely are affected by the number of children and their gender composition so we control for the number of children as well as the explicit biases. 


\section{Macrothink

The gender biases for children may also vary by religion. Boys represent exactly half the children in the Orthodox and Protestant households, but they are a majority in the Muslim families (52 percent). (Note 11) The proportion of boys relative to girls living in urban areas is about 1 percent higher than the proportion of boys living in rural areas and in both areas boys are the majority.

Table 2 presents the summary statistics for all the variables that are used in the conditional estimation of the nutritional status for all children and separately for boys and girls. The share of girls in the sample is 49.1 percent. Overall, 11.8 percent of the children are wasted, 42.3 percent are stunted, and 30.1 percent are underweight, as measured by the corresponding Zscore below two standard deviations. Tests for the differences in the Z-scores of boys and girls as well as between the proportions of malnourished children (Z-score of -2) show a statistically significant difference as boys are more malnourished than girls.

Table 2. Means and Welch's Test by Child Gender

\begin{tabular}{lllll}
\hline & All & Boy & Girl & Difference \\
\hline Wasting * & 0.118 & 0.133 & 0.102 & $0.031^{* * *}$ \\
Stunting * & 0.423 & 0.439 & 0.407 & $0.032^{* * *}$ \\
Underweight * & 0.301 & 0.320 & 0.282 & $0.038^{* * *}$ \\
Weight/height std. & -0.627 & -0.686 & -0.566 & $-0.120^{* * *}$ \\
Height/age std. & -1.608 & -1.656 & -1.558 & $-0.089^{* * *}$ \\
Weight/age std. & -1.360 & -1.404 & -1.315 & $-0.098^{* * *}$ \\
Rural & 0.841 & 0.838 & 0.844 & -0.006 \\
Drought area & 0.316 & 0.308 & 0.324 & -0.016 \\
Family wealth score & -3.247 & -3.293 & -3.198 & -0.095 \\
Mothers' education (years) & 1.507 & 1.520 & 1.500 & 0.020 \\
Fathers' education (years) & 2.927 & 2.9370 & 2.9166 & 0.020 \\
Mother's age & 29 & 29.6 & 29.3 & 0.300 \\
Father's age & 37 & 37.3 & 36.8 & $0.500^{* * *}$ \\
Household size (\# members) & 6.185 & 6.106 & 6.163 & -0.057 \\
Number of children in the family & 3.780 & 3.813 & 3.746 & $0.067^{*}$ \\
Female household head & 0.176 & 0.180 & 0.173 & 0.007 \\
Access to pipe water & 0.253 & 0.255 & 0.251 & 0.004 \\
Access to well water & 0.218 & 0.222 & 0.214 & 0.008 \\
Milk consumption & 0.176 & 0.222 & 0.214 & 0.008 \\
Meat consumption & 0.023 & 0.025 & 0.022 & 0.003 \\
Muslim religion & 0.458 & 0.465 & 0.451 & $0.014^{*}$ \\
Orthodox religion & 0.314 & 0.311 & 0.312 & -0.001 \\
Protestant Religion & 0.198 & 0.201 & 0.1974 & 0.004 \\
Observations & $\mathbf{9 4 5 0}$ & $\mathbf{4 8 0 8}$ & $\mathbf{4 6 4 2}$ & \\
\hline Indiates proporton & & &
\end{tabular}

* Indicates proportion of children with Z-score $<-2$ 
We estimate a reduced-form demand function for nutrition, derived from the standard Baker's household utility function of consumer demand and Grossman's health production function (Behrman and Deolalikar, 1988; Baker, 1981; Grossman 1972). Using independent variables that measure household resources, access to food, health environment, etc. allows assessing whether differences in the underlying factors, and specifically gender differences in the associations between these factors and anthropometric status.

Wealth is an important indicator of the ability of the family to feed their children, which is consistent with expenditure and income measures (Rutstein, 1999). We measure family wealth with an index factor score that the designers of the survey created. This variable is a continuous measure that is widely used in DHS country-level surveys and ranges from -22 to 39 with a mean of 3.23. (Note 12) The level of parental education is also likely to affect parents' ability to feed their children. The average years of education for parents is 2.92 years. (Note 13) We also control for the specific age of the child. Children at 0-12 months, ages one to two, two to three, three to four, and four to five (49-60 months of age) represent 20.4 percent, 18.6 percent, 19.5 percent, 21.3 percent and 20.3 percent of all children, respectively. (Note 14)

The vast majority of the children ( 84.1 percent) live in rural areas because the Ethiopian economy relies mostly on agriculture. Since agriculture is predominantly rain-fed, weather and droughts may affect child malnutrition. To eliminate the possibility that our results are affected by drought in the years leading up to the interview, we describe the drought patterns. We observe that rainfall in the year of the data collection was not particularly different from other years for Ethiopia (Figure 1). We control for the possible effect of drought with a dummy variable that takes the value of one if the area in which the household lives is historically prone to drought. About a quarter (25.8 percent) of the households are located in drought-prone areas.

To further measure access to food, we use several dummies. Milk is a dummy variable equal to one if parents gave the observed child milk in the previous week - either tinned, powdered, or fresh and zero otherwise. Only 17.5 percent of the households were able to offer milk. Meat is also a dummy variable that equals one if the parents gave the observed child meat (beef, pork, lamb, chicken, etc.). This variable indicates that only 2 percent of the households were able to offer meat to the child in the previous week.

The Welch t-test for unequal variances shows that while malnutrition rates were different among genders, the remaining variables that capture other living conditions - family wealth, parents' education, and access to key nutrients (milk, meat) — are not significantly different by gender.

\section{Estimation Results}

We begin the analysis by using stunting, wasting, and being underweight as the response variables. The dataset is divided into two groups by gender. First, we run a separate regression for girls only. Next, we calculate the predicted probabilities $(\widehat{P r})$ for the whole dataset. In this process of decomposition, we obtain the predicted probability of being stunted, underweight, or wasted for girls that is denoted as $\operatorname{Pr}^{g}$ in equation (4), as well as the probability of boys' 
being stunted, underweight, or wasted if they were treated like girls $\left(\operatorname{Pr}^{b \mid g}\right)$. Next, we repeat this process for the group of boys to obtain $\mathrm{Pr}^{b}$, the predicted probability of boys being malnourished, as well as the probability $\quad \operatorname{Pr}^{g \mid b}$ of girls being malnourished if they are treated like boys.

Using equation (7), we calculate the endowment and interaction differences and report these values at the bottom of Table 3 following the regular estimates. The first set of two columns in the table contains coefficient estimates of the logistic regression in which the dependent variable is wasting. The second set of two columns presents the results from a logistic regression in which stunting is the dependent variable. The third set of columns contains the results for being underweight. The coefficients are log of the odds ratios so we discuss their exponentiated values (marginals) below. All regressions are clustered at the household unit.

Table 3. Logistic Regression of Children's Wasting, Stunting, and Being Underweight

\begin{tabular}{|c|c|c|c|c|c|c|}
\hline & \multicolumn{2}{|l|}{ Wasting } & \multicolumn{2}{|l|}{ Stunting } & \multicolumn{2}{|c|}{ Underweight } \\
\hline & Boys & Girls & Boys & Girls & Boys & Girls \\
\hline \multirow[t]{2}{*}{ Rural } & $-0.53 * * *$ & -0.297 & 0.191 & 0.063 & 0.014 & -0.279 \\
\hline & $(0.203)$ & $(0.238)$ & $(0.155)$ & $(0.166)$ & $(0.163)$ & $(0.199)$ \\
\hline \multirow[t]{2}{*}{ Drought } & -0.036 & $0.539^{*}$ & $0.378^{*}$ & 0.119 & 0.303 & 0.043 \\
\hline & $(0.306)$ & $(0.327)$ & $(0.207)$ & $(0.214)$ & $(0.256)$ & $(0.267)$ \\
\hline \multirow[t]{2}{*}{ Rural * Drought } & 0.052 & -0.466 & -0.070 & -0.000 & -0.100 & 0.232 \\
\hline & $(0.318)$ & $(0.349)$ & $(0.225)$ & $(0.236)$ & $(0.265)$ & $(0.287)$ \\
\hline \multicolumn{7}{|l|}{ Age } \\
\hline \multirow[t]{2}{*}{$1-2$} & 0.141 & 0.280 & $1.307 * * *$ & $0.882 * * *$ & $0.358^{* *}$ & $0.569 * * *$ \\
\hline & $(0.208)$ & $(0.240)$ & $(0.175)$ & $(0.170)$ & $(0.170)$ & $(0.191)$ \\
\hline \multirow[t]{2}{*}{$2-3$} & -0.412 & 0.112 & $1.106^{* * *}$ & $0.674^{* *}$ & -0.053 & 0.287 \\
\hline & $(0.360)$ & $(0.421)$ & $(0.275)$ & $(0.283)$ & $(0.279)$ & $(0.298)$ \\
\hline \multirow[t]{2}{*}{$3-4$} & -0.542 & 0.407 & 0.563 & -0.215 & $-0.795^{* *}$ & -0.274 \\
\hline & $(0.525)$ & $(0.590)$ & $(0.385)$ & $(0.393)$ & $(0.393)$ & $(0.419)$ \\
\hline \multirow[t]{2}{*}{$4-5$} & -0.351 & 1.027 & -0.145 & $-1.310 * *$ & $-1.370 * * *$ & -0.877 \\
\hline & $(0.674)$ & $(0.791)$ & $(0.502)$ & $(0.518)$ & $(0.522)$ & $(0.548)$ \\
\hline \multirow[t]{2}{*}{ Wealth } & $-0.068 * * *$ & $-0.077 * * *$ & $-0.044 * * *$ & $-0.047 * * *$ & $-0.085^{* * *}$ & $-0.078 * * *$ \\
\hline & $(0.016)$ & $(0.018)$ & $(0.011)$ & $(0.011)$ & $(0.013)$ & $(0.013)$ \\
\hline \multirow[t]{2}{*}{ Mother Education } & -0.017 & 0.000 & -0.013 & -0.023 & $-0.039 * *$ & $-0.046^{* *}$ \\
\hline & $(0.026)$ & $(0.028)$ & $(0.017)$ & $(0.019)$ & $(0.019)$ & $(0.021)$ \\
\hline \multirow[t]{2}{*}{ Father education } & $-0.033^{* *}$ & -0.007 & $-0.020^{*}$ & $-0.023 *$ & -0.007 & -0.013 \\
\hline & $(0.017)$ & $(0.018)$ & $(0.011)$ & $(0.012)$ & $(0.013)$ & $(0.013)$ \\
\hline \multirow[t]{2}{*}{ Mother age } & -0.011 & $-0.036^{* *}$ & $0.037 * * *$ & $0.067 * * *$ & $0.043 * * *$ & $0.044 * * *$ \\
\hline & $(0.014)$ & $(0.016)$ & $(0.010)$ & $(0.011)$ & $(0.010)$ & $(0.011)$ \\
\hline \multirow[t]{2}{*}{ Father age } & 0.001 & $0.012^{* *}$ & -0.002 & -0.002 & 0.001 & $0.008^{*}$ \\
\hline & $(0.005)$ & $(0.006)$ & $(0.004)$ & $(0.004)$ & $(0.004)$ & $(0.004)$ \\
\hline \# living children & 0.007 & -0.012 & -0.006 & -0.032 & -0.030 & $-0.053 * *$ \\
\hline
\end{tabular}




\begin{tabular}{|c|c|c|c|c|c|c|}
\hline & $(0.034)$ & $(0.036)$ & $(0.026)$ & $(0.025)$ & $(0.026)$ & $(0.026)$ \\
\hline \multirow[t]{2}{*}{ Household size } & -0.031 & 0.007 & -0.015 & 0.024 & 0.002 & 0.004 \\
\hline & $(0.031)$ & $(0.030)$ & $(0.020)$ & $(0.021)$ & $(0.021)$ & $(0.021)$ \\
\hline \multirow[t]{2}{*}{ Head Female } & $0.283 * *$ & 0.223 & $0.195 * *$ & 0.134 & 0.145 & $0.237 * *$ \\
\hline & $(0.123)$ & $(0.151)$ & $(0.096)$ & $(0.109)$ & $(0.096)$ & $(0.115)$ \\
\hline \multirow[t]{2}{*}{ Home appliances } & 0.105 & -0.183 & -0.106 & -0.017 & 0.181 & -0.031 \\
\hline & $(0.239)$ & $(0.282)$ & $(0.177)$ & $(0.180)$ & $(0.198)$ & $(0.223)$ \\
\hline \multirow[t]{2}{*}{ Piped water } & 0.179 & $0.344 * *$ & -0.039 & -0.019 & 0.107 & 0.142 \\
\hline & $(0.134)$ & $(0.155)$ & $(0.106)$ & $(0.102)$ & $(0.107)$ & $(0.114)$ \\
\hline \multirow[t]{2}{*}{ Well water } & 0.020 & -0.017 & -0.116 & 0.027 & -0.087 & 0.075 \\
\hline & $(0.111)$ & $(0.136)$ & $(0.086)$ & $(0.090)$ & $(0.086)$ & $(0.092)$ \\
\hline \multirow[t]{2}{*}{ Milk consumption } & 0.007 & 0.175 & $-0.467 * * *$ & $-0.253 * *$ & $-0.233 * *$ & -0.152 \\
\hline & $(0.114)$ & $(0.132)$ & $(0.095)$ & $(0.099)$ & $(0.095)$ & $(0.111)$ \\
\hline \multirow[t]{2}{*}{ Meat consumption } & -0.212 & -0.199 & -0.093 & 0.281 & -0.250 & -0.039 \\
\hline & $(0.328)$ & $(0.395)$ & $(0.197)$ & $(0.252)$ & $(0.233)$ & $(0.294)$ \\
\hline \multirow[t]{2}{*}{ Orthodox religion } & $-0.244 *$ & $-0.288 * *$ & 0.014 & 0.049 & $-0.182 *$ & $-0.265 * *$ \\
\hline & $(0.138)$ & $(0.143)$ & $(0.097)$ & $(0.105)$ & $(0.099)$ & $(0.109)$ \\
\hline \multirow[t]{2}{*}{ Protestant religion } & $-0.390 * * *$ & -0.216 & -0.042 & $-0.246 * *$ & $-0.429 * * *$ & $-0.367 * * *$ \\
\hline & $(0.132)$ & $(0.161)$ & $(0.097)$ & $(0.097)$ & $(0.105)$ & $(0.116)$ \\
\hline Ideal \# Girls Dummies & Yes & Yes & Yes & Yes & Yes & Yes \\
\hline \multirow[t]{2}{*}{ Constant } & $-0.736 * *$ & $-2.083 * * *$ & $-2.089 * * *$ & $-2.401 * * *$ & $-1.714 * * *$ & $-2.213 * * *$ \\
\hline & $(0.350)$ & $(0.371)$ & $(0.265)$ & $(0.273)$ & $(0.261)$ & $(0.301)$ \\
\hline Observations & 4508 & 4315 & 4511 & 4320 & 4511 & 4317 \\
\hline Pseudo R2 & 0.05 & 0.06 & 0.13 & 0.12 & 0.08 & 0.07 \\
\hline Endowment diff & $0.002 *$ & & 0.003 & & 0.004 & \\
\hline Coefficient diff & $0.030 * * *$ & & $0.028 * * *$ & & $0.039 * * *$ & \\
\hline $\mathrm{CE}$ & 0.000 & & $-0.003^{*}$ & & -0.001 & \\
\hline
\end{tabular}

Standard errors in parentheses “* $\mathrm{p}<0.1, * * \mathrm{p}<0.05, * * * \mathrm{p}<0.01$ ”

First, we expect that the malnutrition rate in rural and drought-prone areas is higher than the malnutrition rate in urban and non-drought areas, yet our results are somewhat surprising. Compared to boys in urban areas, rural boys have 41 percent lower odds of being wasted, while girls are unaffected. A possible explanation is that, although we control for wealth, a significant proportion of the urban population may still be poorer than the rural population in real terms due to higher costs of living in cities. As expected, living in drought-prone areas increases the odds of stunting for boys by 46 percent and the odds of wasting for girls by 71 percent compared to children living in non-drought prone areas, suggesting short-term malnutrition differences (wasting) for girls but long-term malnutrition differences for boys. There is no difference in the probabilities of being underweight in rural/urban and (non-)drought areas.

The results confirm the expectation that children from wealthier and more educated households are better nourished. For all three malnutrition measures, household wealth has a significantly positive effect on children's nutrition status. Moreover, the family wealth impacts are almost 
identical for boys and girls, and the association is greater with wasting and being underweight (marginal effect of 7 to 8 percent) relative to stunting (4 percent). An extra year of father's education reduces the odds of stunting in boys and girls and of wasting in boys by about 2 percent and mother's education also reduces the odds of being underweight. These results confirm that policies of promoting education and employment opportunities can lead to better nutritional outcomes for young children.

The mother's and father's ages may have two countervailing effects. On the one hand, age represents more experience with raising children. On the other hand, advancing age may be associated with declining productivity and health that may affect both pregnancy outcomes and child health. We find that an additional year of mother's age is associated with 3.6 percent lower odds of a daughter being wasted but 4 percent to 7 percent higher odds of being stunted or being underweight for both boys and girls. While the short-term effect may indicate that older mothers are feeding their daughters better, the underlying biological component associated with the age of the mother may be contributing to the overall less healthier daughters. Predictably, the effects of the father's age are smaller and marginally significant.

Consistent with these findings is the estimate for the female head of household. In households with a female head, boys have 33 percent higher odds of being wasted and 22 percent higher odds of being stunted (associated with long-term effects of malnutrition), while girls have 27 percent higher odds of being underweight (associated with short-term effect). These results are likely driven by higher demand on the time of the female head of household who might also be a single mother. Contrary to expectations, the household size has no effect on malnutrition. The only effect of the water supply is that piped water increases the odds of being wasted by 41 percent for girls. This raises questions about the quality of piped water or possibly about the value of girls when water is more readily available.

Access to milk decreases the odds of stunting by 37 percent and 22 percent for boys and girls, respectively, and the odds of being underweight by 21 percent for boys. However, the consumption of meat does not affect the nutrition status because of the young age of the children in the sample and because so few families can afford it. (Note 15)

We created five age dummies for children's age below five and included them in a regression in whith the base level of less than 12 months old. Overall, children ages 13 to 36 months are significantly more likely to be stunted with the difference much more pronounced for boys, which may have early growth related physiological reasons consistent with previous work (Black et al., 2013). At the same time, closer to the age of five, girls are much less likely to be stunted while boys are less likely to be underweight.

We controlled for the parent's explicit preferences towards the child's gender by including their answer to the question of what the ideal number of girls was. (Note 16) We do not find significant differences in the stated preferences relative to the base, which is the respondents who answered zero was the optimal number of girls (13 percent of the responding parents). This finding indicates that a potential difference in the biases is not captured by an explicit answer to this question. (Note 17) 
Of special interest is the last part of Table 3, which shows that for the three types of malnutrition the endowment (explained) difference is close to zero and is not statistically significant, except for wasting with the small value of 0.002 . The results are mostly consistent with the Welch test results of no differences in the independent socio-environmental variables that influence the inequality between girls and boys (Table 2). This suggests that the observed differences in malnutrition do not come from differences in the living conditions since the interaction terms between the coefficients and endowments (CE) are also not statistically significantly different for wasting and being underweight. They are different only in the case of stunting (-0.003), suggesting a very small long-term malnutrition effect.

The most interesting result shows that the coefficient differences in Table 3 are positive and statistically significant for all three measures of malnutrition. Controlling for living conditions and home characteristics, if the girls were fed like boys, their odds of being wasted would increase by 3.1 percent. (Note 18) In the same setup, girls' odds of being stunted and underweight would increase by 2.8 percent and 4 percent, respectively. These results indicate that, overall, girls in the surveyed sample were less malnourished than boys and this is not explained by the measurable differences in the endowments. The only caveat that we want to point out is that, as children approach the age of five, the share of girls drops and they represent 47 percent or children age five. Assuming this pattern holds over time (our data are crosssectional), this observed difference in survival by the age of five could explain our results if fewer girls who survived and were observed were in fact fed better than boys who survived to age five.

As a robustness check, we also estimated models for the continuous estimated Z-score and decomposing the estimates. The results are presented in Table 1 in the Appendix and are consistent with those in Table 3. The endowment difference is significant only for wasting and is negative and small in magnitude. The coefficient difference ( $C=Z^{g \mid b}-Z^{g}$ ), shows that, if the girls were treated as if they were boys, their stunting Z-score would decrease by 0.123 , their wasting score by 0.098 , while their underweight score would be unaffected. These results suggest that the girls' better nourishment is mostly attributable to parental or societal biases, or other unexplained factors.

Between 2005 and 2011, there was a significant drop in nutrition related mortality among children under the age of five in Ethiopia (Ambel et al., 2015). This drop might have been due to the overall better effort and disseminating the knowledge of how to feed children. However, the sudden overall improvement in Z-scores of girls at the age of five combined with the fact that girls at this age were only 47 percent of the sample may suggest that fewer girls than boys had survived, in contrast to official statistics of lower survival rates for boys. If that is the case, then the results could not be interpreted as girls being fed better but rather suggest that only concerted efforts to better nourish girls could ensure that they survive beyond the age of five in the same proportion as boys. 
4.1 Robustness Checks

Table 4. Quantile Decomposition

\begin{tabular}{|c|c|c|c|c|c|}
\hline \multicolumn{6}{|l|}{ Quantiles } \\
\hline & Q 0.1 & Q 0.2 & Q 0.3 & Q 0.4 & Q 0.5 \\
\hline \multicolumn{6}{|c|}{ Wasting Weight-for height } \\
\hline Raw difference & $-0.22 * * *$ & $-0.19 * * *$ & $-0.16^{* * *}$ & $-0.13 * * *$ & $-0.11 * * *$ \\
\hline Characteristics & -0.01 & -0.01 & -0.01 & -0.01 & -0.01 \\
\hline Coefficients & $-0.21 * * *$ & $-0.17 * * *$ & $-0.15^{* * *}$ & $-0.13 * * *$ & $-0.10 * * *$ \\
\hline \multicolumn{6}{|c|}{ Stunting Height for Age) } \\
\hline Raw difference & $-0.08^{* *}$ & $-0.12 * * *$ & $-0.12 * * *$ & $-0.11 * * *$ & $-0.1 * * *$ \\
\hline Characteristics & -0.02 & -0.02 & -0.02 & -0.02 & -0.02 \\
\hline Coefficients & $-0.06^{* *}$ & $-0.10 * * *$ & $-0.10 * * *$ & $-0.09 * * *$ & $-0.08 * * *$ \\
\hline \multicolumn{6}{|l|}{ Underweight } \\
\hline \multicolumn{6}{|l|}{ Weight for Age } \\
\hline Raw difference & $-0.09 * *$ & $-0.11 * * *$ & $-0.13 * * *$ & $-0.13 * *$ & $-0.10 * * *$ \\
\hline Characteristics & -0.02 & -0.01 & -0.02 & -0.02 & -0.02 \\
\hline Coefficients & $-0.08^{* * *}$ & $-0.10 * * *$ & $-0.11 * * *$ & $-0.11^{* * *}$ & $-0.09 * * *$ \\
\hline \multicolumn{6}{|l|}{ Quantiles } \\
\hline & Q 0.6 & Q 0.7 & Q 0.8 & Q 0.9 & \\
\hline \multicolumn{6}{|c|}{ Wasting Weight-for height } \\
\hline Raw difference & $-0.11^{* * *}$ & $-0.08 * * *$ & $-0.06 * * *$ & $-0.08^{* * *}$ & \\
\hline Characteristics & -0.01 & -0.01 & -0.01 & -0.01 & \\
\hline Coefficients & $-0.1 * * *$ & $-0.07 * * *$ & $-0.06 * * *$ & $-0.08 * * *$ & \\
\hline \multicolumn{6}{|c|}{ Stunting Height for Age) } \\
\hline Raw difference & $-0.09 * * *$ & $-0.10 * * *$ & $-0.09 * *$ & -0.08 & \\
\hline Characteristics & -0.01 & -0.01 & -0.00 & 0.00 & \\
\hline Coefficients & $-0.08 * * *$ & $-0.08 * *$ & $-0.08 * *$ & -0.08 & \\
\hline \multicolumn{6}{|l|}{ Underweight } \\
\hline \multicolumn{6}{|l|}{ Weight for Age } \\
\hline Raw difference & $-0.09 * * *$ & $-0.09 * *$ & $-0.09^{* * *}$ & $-0.09 * * *$ & \\
\hline Characteristics & -0.01 & -0.01 & -0.01 & 0.00 & \\
\hline Coefficients & $-0.07 * * *$ & $-0.07 * * *$ & $-0.08 * * *$ & $-0.08 * *$ & \\
\hline
\end{tabular}

*** Significant at 95 percent level. Characteristics refers to differences due to characteristics or covariates effect, while coefficient refers to differences in parental biases (discrimination).

In addition to the analysis described above, we also investigate malnourishment using the Machado and Mada (2005) quantile approach by which the unexlpained bias/discriminaton is computed for the quantiles of the dependent variable. The results are presented in Table 4. Consistent with the main result, we find no differences due to the endownment effect but statistically significant differences due to the coefficients (unexplianed) differences that may 
be attributable to differences in parental attitudes or possibly to biological differences. These results are for the continuous measure of maluntrition with higher values indicating better nutrition except for the largest percentile where it may indicate being overweight. We find that the largest raw diference betweeen boys and girls is in wasting for the lowest quantiles. Specifically, the unexplained difference for the $90^{\text {th }}$ percentile and above is about 2.5 times smaller than that for the $10^{\text {th }}$ percentile, which might indicate that implicit parental, societal, and other biases for girls over boys decrease as children nutrition improves. This finding also suggests that the reliance on the simple Oaxaca-Blinder decomposition can be somewhat misleading in out context because heavier children are generally accepted as healthier.

The last robustness check that we perform has to do with the contribution of individual covariates within the Z-score quantiles as well as the overall effect that uses the Recentered Influence Function (RIF) to compute the counterfactual for percentiles. Significant results for stunting as the most important long-term malnourishment indicator are presented in Tables 2 and 3 in the Appendix for boys and girls, respectively. Boys but not girls in rural areas are more stunted only in the middle quantile and both are affected in drought prone areas. Predictably, household wealth, along with father's education, is positive and significant but slightly decreasing with quantiles. Access to milk is negatively associated with long-term malnourishment, while access to meat is insignificant as before. Relative to children younger than 12 months, stunting is significantly worse for all quantiles and increases with quantiles but varies with age.

The results for wasting and being underweight (not presented to save space) also indicate that parental wealth and fathers' education are associated with better nutritional outcomes of magnitude that slightly declines with percentiles. (Note 19) While drought exposure has a marginal negative effect, rural children are significantly less wasted, particularly boys in the lower quantiles. Surprisingly, milk consumption has minimal and marginally significant impact ranging from slightly positive on wasting in boys to slightly negative on being underweight in all children. While wasting seems to decrease with age suggesting that children become more resilient to short term shocks, being underweight increases with age for both boys and girls with larger coefficients in higher percentiles after the age of two. This is possibly because babies are protected by breastfeeding.

\section{Conclusions}

In this paper, we use data on child malnutrition from the Demographic and Health Survey in Ethiopia to establish whether differences in the malnutrition rates of boys and girls are attributable to endowment, socio-economic factors, or other unobservable factors such as parental and societal preferences. We use the Oaxaca decomposition method to explain gender differences in terms of three standard malnutrition (anthropometric status) measures in a logistic regression and for continuous Z-scores. Robustness checks apply the extension by Machado and Mata (2005) and their decomposition technique to identify differences in gender malnutrition by quantiles of the dependent variable. Further, the individual contribution of each covariate to the malnutrition of boys and girls by quantiles is estimated with Firpo et al. (2007, 
2009) recentered influence function approach.

We find that, up to the age of five, some of the differences in anthropometric status between boys and girls cannot be explained by the endowment differences, suggesting possible role for unobservable factors such as implicit parental, societal, and cultural biases. Specifically, controlling for all covariates, if a girl is treated as if she were a boy, the odds of her being wasted increase by 3.1 percent, the odds of being stunted by 2.8 percent, and the odds of being underweight by 4 percent. Several robustness checks confirm these results. The finding that surviving girls have better nutritional status is consistent with the higher under five mortality rates for boys in Ethiopia (World Bank and UNICEF). It is also in line with studies finding that girls are less likely to be malnourished than boys in Sub-Saharan Africa (Garrett and Ruel, 1999) and that food aid is distributed differently between boys and girls (Quisumbing, 2003).

Consistent with previous work, we also find that family wealth is important in supporting a child's nutrition status, which supports the view that investment in education would have a long lasting effect in the future to mitigate child malnutrition in Ethiopia. While many policies target food security in rural East Africa, our analysis indicates better nutrition outcomes for children living in rural relative to urban areas, whereas droughts seem to affect the malnutrition of all children and not only those living in drought prone rural areas.

The differences in gender outcomes that we find and the finding that they may be attributable to gender preferences or societal biases have policy relevant implications. The results could be used to enhance the effectiveness of government programs such as the five year Sustainable Undernutrition Reduction in Ethiopia (SURE) program. The SURE follows key recommendations by the WHO to make behavior change communication central to strategies to improve infant and young child feeding by influencing the knowledge, attitudes, beliefs, and social norms that underpin dietary practices (Worku, 2020). Yet, while the gendered roles of parents are an essential component of the program (e.g., both parents attend some sessions), the differences in nutritional outcomes for boys and girls are not part of it (Moss et al., 2018).

Our finding that a small but significant difference in malnutrition between boys and girls is not fully explained by the conventional socio-economic factors, including explicitly stated parental preferences such as the preference for an ideal number of girls in a family. Thus, the results may be attributable to implicit or latent gender preferences, societal biases, and other unobservables, which warrants further exploration of this issue beyond Ethiopia. Future work could use similar methods to test hypotheses for parental preferences and biases influencing gender differences in anthropometric status in other developing countries across the world, as well as other outcomes of human capital development such as education and health.

\section{References}

Ambel, A.A., C. Andrews, A. M. Bakilana, E. Foster, Q. Khan \& H. Wang. (2015). Maternal and Child Health Inequalities in Ethiopia. Washington, DC. (C) World Bank. https://openknowledge.worldbank.org/handle/10986/23805 License: CC BY 3.0 IGO. 
Atsbeha, D. M., R. M. Nayga and K. Rickertsen. (2015). Can prolonged breastfeeding duration impair child growth? Evidence from rural Ethiopia. Food Policy, 53, 46-53. https://doi.org/10.1016/j.foodpol.2015.03.010

Becker, G. S. (1981). A treatise on the family. Cambridge, Mass: Harvard University Press.

Behrman, J. R., \& A. B. Deolalikar. (1988). Health and nutrition, Handbook of Development Economics. In: Hollis Chenery \& T.N. Srinivasan (Ed.), Handbook of Development Economics, edition 1, volume 1, chapter 14, pages 631-711, Elsevier.

Behrman, J. R. (1988). Nutrition, health, birth order and seasonality: Intrahousehold allocation among children in rural India. Journal of Development Economics, 28(1), 43-62. https://doi.org/10.1016/0304-3878(88)90013-2

Bellemare, M. F., C. B. Barrett \& D. R. Just. (2013). The Welfare Impacts of Commodity Price Volatility: Evidence from Rural Ethiopia. American Journal of Agricultural Economics, 95(4), 877-899.

Blinder, A. (1973). Wage discrimination: reduced form and structural estimates. Journal of Human resources, 8, 427-451.

Black, R. E., C. G. Victora \& S. P. Walker, et al. (2013). Maternal and child undernutrition and overweight in low-income and middle-income countries. Lancet, 382(9890), 427-451. https://doi.org/10.1016/S0140-6736(13)60937-X

Block, S., \& P. Webb. (2009). Up in Smoke: Tobacco Use, Expenditure on Food, and Child Malnutrition in Developing Countries. Economic Development and Cultural Change, 58(1), 1-23. https://doi.org/10.1086/605207

Bork, K. A., \& A. Diallo. (2017). Boys are more stunted than girls from early infancy to 3 years of age in rural Senegal. The Journal of Nutrition, 147(5), 940-947. https://doi.org/10.3945/jn.116.243246

Daymont, T. N., \& P. J. Andrisani. (1984). Job Preferences, College Major, and the Gender Gap in Earnings. The Journal of Human Resources, 19(3), 408. https://doi.org/10.2307/145880

Dinardo, John, Fortin, Nicole \& Lemieux, Thomas. (1996). Labor Market Institutions and The Distribution of Wages, 1973-1993: A Semi-Parametric Approach. Econometrica, 64, 1001-44. https://doi.org/10.2307/2171954

Ethiopian Demographic and Health Survey. (2011). Addis Ababa, Central Statistics Agency; Calverton Maryland, ICF Macro, 2011. Retrieved 03/29/2020 from https://dhsprogram.com/publications/publication-fr255-dhs-final-reports.cfm

FAO. (2020). Evaluation of FAO's country programme in Ethiopia 2014-2019. Country Programme Evaluation Series, 10/2020. Rome. Retrieved 05/15/2021 from http://www.fao.org/publications/card/en/c/CB1354EN/

Firpo, S., N. Fortin \& T. Lemieux. (2009) Unconditional Quantile Regressions. Econometrica, 
77(3), 953-973. https://doi.org/10.3982/ECTA6822

Firpo, S., N. Fortin \& T. Lemieux. (2007). Decomposing Wage Distributions Using Recentered Influence Function Regressions. Unpublished Manuscript, University of British Columbia. Retrieved from http://citeseerx.ist.psu.edu/viewdoc/download?doi=10.1.1.344.2035\&rep=rep1\&type=pd $\mathrm{f}$

Garrett, J. L., \& M.T. Ruel. (1999). Are determinants of rural and urban food security and nutritional status different? Some insights from Mozambique. World Development, 27(11), 1955-1975. https://doi.org/10.1016/S0305-750X(99)00091-1

Grossman, M. (1972). On the concept of health capital and the demand for Health. J Polit Econ., $80,223-55$.

Headey, D. (2014). An Analysis of Trends and Determinants of Child Undernutrition in Ethiopia, 2000-2011. Washington, DC: International Food Policy Research Institute.

Headey, D., J. Hoddinott, \& S. Park. (2017). Accounting for nutritional changes in six success stories: A regression-decomposition approach. Global Food Security, 13, 12-20. https://doi.org/10.1016/j.gfs.2017.02.003

Hirvonen, K. (2016). Rural-urban differences in children's dietary diversity in Ethiopia: a Poisson decomposition analysis. Economics Letters, 147, 12-15. https://doi.org/10.1016/j.econlet.2016.08.003

Jayachandran, S., \& I. Kuziemko. (2011). Why do mothers breastfeed girls less than boys? Evidence and implications for child health in India. The Quarterly Journal of Economics, 126(3), 1485-1538. https://doi.org/10.1093/qje/qjr029

Jayachandran, S., \& R. Pande. (2017). Why are Indian children so short? The role of birth order and son preference. American Economic Review, 107(9), 2600-2629. https://doi.org/10.1257/aer.20151282

Johnston, C., L. Belschner, J. L. Park, K. Stewart, A. Noyes \& M. Schaller. (2017). Mothers' Implicit and Explicit Attitudes and Attributions in Relation to Self-Reported Parenting Behavior. Parenting, 17(1), 51-72. https://doi.org/10.1080/15295192.2016.1184954

Klasen, S. (1996). Nutrition, health and mortality in sub-Saharan Africa: Is there a gender bias? The Journal of Development Studies, 32(6), 913-932. https://doi.org/10.1080/00220389608422446

Kynch, J., \& A. Sen, (1983) Indian women: well-being and survival. Cambridge Journal of Economics, 7(3-4), 363-380. https://doi.org/10.1093/cje/7.3-4.363

Koohi-kamali, F. (2008). Intrahousehold Inequality and Child Gender Bias in Ethiopia. World Bank Policy Research Working Paper Series 4755, The World Bank. Handle: RePEc:wbk:wbrwps:4755

Lazzaroni, S., \& N. Wagner. (2016). Misfortunes never come singly: Structural change, 
multiple shocks and child malnutrition in rural Senegal. Economics \& Human Biology, 23, 246-262. https://doi.org/10.1016/j.ehb.2016.10.006

Lintelo, D. J. H., \& R. W. D. Lakshman. (2015). Equate and Conflate: Political Commitment to Hunger and Undernutrition Reduction in Five High-Burden Countries. World Development, 76, 280-292. https://doi.org/10.1016/j.worlddev.2015.07.013

Lydecker, J.A., E. O'Brien, \& C.M. Grilo. (2018). Parents have both implicit and explicit biases against children with obesity. J Behav Med., 41(6), 784-791. https://doi.org/10.1007/s10865-018-9929-4.

Machado, J. A., \& J. Mata. (2005). Counterfactual decomposition of changes in wage distributions using quantile regression. Journal of applied Econometrics, 20(4), 445-465. https://doi.org/10.1002/jae.788

May, J., \& I. M. Timæus. (2014). Inequities in under-five child nutritional status in South Africa: What progress has been made? Development Southern Africa 31(6), 761-774. https://doi.org/10.1080/0376835X.2014.952896

Mohammed, S. H., F. Muhammad, R. Pakzad, \& S. Alizadeh. (2019). Socioeconomic inequality in stunting among under-5 children in Ethiopia: a decomposition analysis. $B M C$ Research Notes, 12(1), 184. https://doi.org/10.1186/s13104-019-4229-9

Moss, C., T. H. Bekele, M.M. Salasibew, J. Sturgess, G. Ayana, D. Kuche, S. Eshetu, A. Abera, E. Allen, \& A.D. Dangour. (2018). Sustainable Undernutrition Reduction in Ethiopia (SURE) evaluation study: a protocol to evaluate impact, process and context of a largescale integrated health and agriculture programme to improve complementary feeding in Ethiopia. BMJ open, 8(7), e022028. https://doi.org/10.1136/bmjopen-2018-022028

Mussa, R. (2015). Intrahousehold and interhousehold child nutrition inequality in Malawi. South African Journal of Economics, 83(1), 140-153. https://doi.org/10.1111/saje.12060

Oaxaca, R. (1973). Male-female wage differentials in urban labor markets. International Economic Review, 14, 693-709. https://doi.org/10.2307/2525981

Oyekale, A. S. (2014). Factors Explaining Child Survival in Ethiopia: Application of TwoStage Probit Model. African Development Review, 26(2), 237-249. https://doi.org/10.1111/1467-8268.12078

Pulok, M.H., M.N.-U. Sabah, \& U. Enemark. (2016). Socioeconomic inequalities of child malnutrition in Bangladesh. International Journal of Social Economics, 43(12), 14391459. https://doi.org/10.3390/ijerph17031079

Quisumbing, A. R. (2003). Food Aid and Child Nutrition in Rural Ethiopia. World Development, 31(7), 1309-1324. https://doi.org/10.1016/S0305-750X(03)00067-6

Rashad, A., \& M. Sharaf. (2015). Does Economic Growth Reduce Child Malnutrition in Egypt? New Evidence from National Demographic and Health Survey. Working Paper. https://doi.org/10.13140/RG.2.1.4931.7526 
Ren, W., A. Rammohan, \& Y. Wu. (2014). Is there a gender gap in child nutritional outcomes in rural China? China Economic Review, 31, 145-155. https://doi.org/10.1016/j.chieco.2014.09.001

Reshid, A. (2017). Do Parents in Ethiopia Invest More in the Early Health of Sons? : A Study of Breastfeeding, Vaccination and the Role of Unintended Births. Working paper series: Linnaeus University Centre for Discrimination and Integration Studies. Retrieved from https://www.diva-portal.org/smash/record.jsf?pid=diva2\%3A1179003\&dswid=-815

Rutstein, S. (1999). Wealth versus expenditure: Comparison between the DHS wealth index and household expenditures in four departments of Guatemala. Calverton, Maryland: ORC Macro (Unpublished).

Sahn, D. E., \& D.C. Stifel. (2002). Parental preferences for nutrition of boys and girls: evidence from Africa. Journal of Development Studies, 39(1), 21-45. https://doi.org/10.1080/00220380412331322651

Salvucci, V. (2016). Determinants and Trends of Socioeconomic Inequality in Child Malnutrition: The Case of Mozambique, 1996-2011. Journal of International Development, 28(6), 857-875. https://doi.org/10.1002/jid.3135

Seleshi, Y., \& U. Zanke. (2004). Recent changes in rainfall and rainy days in Ethiopia. International Journal of Climatology, 24(8), 973-983. https://doi.org/10.1002/joc.1052

Sinning, M., M. Hahn, \& T. K. Bauer. (2008). The Blinder-Oaxaca decomposition for nonlinear regression models. The Stata Journal, 8(4), 480-492. https://doi.org/10.1177/1536867X0800800402

Smith, L., M. Ruel, \& A. Ndiaye. (2005). Why Is Child Malnutrition Lower in Urban Than in Rural Areas? Evidence from 36 Developing Countries, World Development, 33(8), 12851305. https://doi.org/10.1016/j.worlddev.2005.03.002

Svedberg, P. (1990). Undernutrition in sub-Saharan Africa: Is there a gender bias? Journal of Development Studies, 26(3), 469-486. https://doi.org/10.1080/00220389008422165

Taber, D. R., W. R. Robinson, S. N. Bleich \& Y. C. Wang. (2016). Deconstructing race and gender differences in adolescent obesity: Oaxaca-blinder decomposition. Obesity, 24(3), 719-726. https://doi.org/10.1002/oby.21369

UNICEF Key Demographic Characteristics by country, Ethiopia. Retrieved 03/29/2020 from https://data.unicef.org/country/eth/

Wagstaff, A., \& N. Watanabe. (2003). What difference does the choice of SES make in health inequality measurement? Health Economics, 12(10), 885-890. https://doi.org/10.1002/hec.805

Wamani, H., A.N. Åstrøm, S.Peterson, J. K. Tumwine, \& T. Tylleskär. (2007). Boys are more stunted than girls in sub-Saharan Africa: a meta-analysis of 16 demographic and health surveys. BMC pediatrics, 7(1), 17. https://doi.org/10.1186/1471-2431-7-17 
World Bank Gender Data Portal, Mortality rate under-5, by gender. Retrieved 03/29/2020 from https://datatopics.worldbank.org/gender/indicators

Worku, T., K. A. Gonete, E. A. Muhammad, \& A. Atnafu. (2020). Sustainable under nutrition reduction program and dietary diversity among children's aged 6-23 months, Northwest Ethiopia: Comparative cross-sectional study. International journal for equity in health, 19(1), 14. https://doi.org/10.1186/s12939-019-1120-1

World Food Programme (WFP), and Center for Disease Control and Prevention (CDC). (2005). Defining and Measuring Malnutrition. A Manual: Measuring and Interpurtin malnutrition and Mortality, 1, 15-32.

Zewdie, T., \& D. Abebaw. (2013). Determinants of Child Malnutrition : Empirical Evidence from Kombolcha District of Eastern Hararghe Zone, Ethiopia. Quarterly Journal of International Agriculture, 52(4), 357-372. https://doi.org/10.1186/1471-2431-7-17

\section{Notes}

Note 1. In Ethiopia in 2010, school enrolment was 97 percent for girls and 106 percent for boys in primary education, 32 percent for girls and 39 percent for boys in secondary education, and 4 percent for females and 10 percent for males in tertiary education, according to Work Bank data.

Note 2. These numbers are confirmed by the UNICEF Key Demographic Characteristics database for the country, also showing a significant decline but similar gender differences in time (UNICEF, 2020).

Note 3. A Z-score below three is defined as severe malnutrition for children under five. We found very few studies that used severe malnutrition as their standard. Hence, in this study, we use $2 \mathrm{SD}$ as the critical value to indicate malnutrition.

Note 4. This is survey provides the anthropometric status the Z-scores of children.

Note 5. An unbalanced ratio may be a sample feature or partly due to relative under-recording of births rather than an indication of neglect and poorer survival of girls compared to boys (Kynch and Sen, 1983).

Note 6. We do not observe the implicit/latent preferences of both parents, which of course may differ by parent and may themselves be a function of each parent's individual characteristics (values, cultural and religious background, education).

Note 7. Given that the explicit parental preference measure is imperfect (for example, we do not know if parents are asked "in general" of "for your family" and these are known to be different questions), it is imperfect measure to capture parental preferences. Even if the gender of the respondent were available, the respondent may not be the main person in charge of child nutrition. This variable would also interact with other parents' attributes that may differ by parent in many ways rendering the variable even less useful. 


\section{Macrothink}

Research in Applied Economics

ISSN 1948-5433

2021, Vol. 13, No. 3

Note 8. The specific answer was "Alah's will" revealing the preference among the Muslim population.

Note 9. The largest group of children (19 percent) live in families with five members, followed by the group of children (18 percent) in families with six members, and the groups of children (14 percent each) who live in families with four and seven members.

Note 10. These data may suggest that there may be preferences for boys and "selective stopping rule" that is continuing to have children until there is a boy. However, we find limited correlation (0.15) between stated parental preferences for girls and the number of children. Further, there is a low correlation $(-0.11)$ between the percentage boys in the family (a proxy for having children until a boy born) and the explicit preferences for girls (-0.12)

Note 11. While some there are also Catholic, traditional or other denominations each represents below one percent.

Note 12. For detailed information on how wealth score is computed in the survey, see the 2011 Ethiopia Demographic and Health Survey Report.

Note 13. Here the number of years of education is the sum of the years of each parent.

Note 14. Both education and wealth are used as not necessarily correlated explanatory variables because, as wealth obviously affects food availability and quality, education could be associated with more efficient management of the family budget and the nourishment of children.

Note 15 . Only 221 out of 9,450 children consumed meat, which may explain the lack of significance.

Note 16. To conserve space in that table, we do not provide the separate insignificant coefficients but acknowledge that we included the set of categories with a "Yes"

Note 17. About 10 percent said that they did not have a specific preference and many seem to provide an arbitrary number. We tried various model specifications but were unable to show any systematic relationship, suggesting that stated preferences are not associated with nutritional outcomes. It is likely that we do not observe the implicit/ latent preferences of both parents as well as societal and other biases, which of course may differ by parent and may themselves be a function of each parent's individual characteristics (values, cultural and religious background, education).

Note 18. Calculated by exponentiating the differences in the table as the dependent variable is the log of odds of being malnourished (classified as such with a Z-score value of -2).

Note 19. Results available upon request. 


\section{Appendix}

Table 1. OLS on Z-scores of Wasting, Stunting, and being Underweight

\begin{tabular}{|c|c|c|c|c|c|c|}
\hline & \multicolumn{2}{|c|}{ Wasting (weight-for-height) } & \multicolumn{2}{|c|}{ Stunting (height-for-age) } & \multicolumn{2}{|c|}{ Underweight (weight-for-age) } \\
\hline & Boys & Girls & Boys & Girls & Boys & Girls \\
\hline \multirow[t]{2}{*}{ Rural } & -0.173 & 0.094 & $0.255^{* * *}$ & $0.228 * * *$ & 0.057 & $0.198 * *$ \\
\hline & $(0.110)$ & $(0.108)$ & $(0.083)$ & $(0.084)$ & $(0.083)$ & $(0.089)$ \\
\hline \multirow[t]{2}{*}{ Drought } & $-0.307 * *$ & -0.064 & -0.063 & -0.113 & $-0.230 * *$ & -0.114 \\
\hline & $(0.125)$ & $(0.125)$ & $(0.100)$ & $(0.104)$ & $(0.101)$ & $(0.099)$ \\
\hline \multirow[t]{2}{*}{ Rural * Drought } & 0.008 & -0.109 & -0.024 & -0.012 & 0.013 & -0.073 \\
\hline & $(0.138)$ & $(0.140)$ & $(0.110)$ & $(0.112)$ & $(0.108)$ & $(0.108)$ \\
\hline \multirow[t]{2}{*}{ Age of child $=1$} & $-0.855^{* * *}$ & $-0.620 * * *$ & 0.033 & -0.038 & $-0.242 * * *$ & $-0.164 * *$ \\
\hline & $(0.119)$ & $(0.111)$ & $(0.091)$ & $(0.083)$ & $(0.091)$ & $(0.083)$ \\
\hline \multirow[t]{2}{*}{ Age of child $=2$} & $-0.639 * * *$ & $-0.326^{*}$ & $0.396 * * *$ & $0.278 * *$ & 0.126 & 0.208 \\
\hline & $(0.196)$ & $(0.184)$ & $(0.146)$ & $(0.136)$ & $(0.145)$ & $(0.139)$ \\
\hline \multirow[t]{2}{*}{ Age of child $=3$} & 0.089 & $0.545 * *$ & $0.605 * * *$ & 0.238 & $0.649 * * *$ & $0.673 * * *$ \\
\hline & $(0.275)$ & $(0.256)$ & $(0.207)$ & $(0.192)$ & $(0.204)$ & $(0.200)$ \\
\hline \multirow[t]{2}{*}{ Age of child $=4$} & $0.858 * *$ & $1.529 * * *$ & $0.592 * *$ & 0.148 & $1.078 * * *$ & $1.218 * * *$ \\
\hline & $(0.366)$ & $(0.339)$ & $(0.268)$ & $(0.255)$ & $(0.269)$ & $(0.264)$ \\
\hline \multirow[t]{2}{*}{ Wealth } & $0.030 * * *$ & $0.035 * * *$ & $0.037 * * *$ & $0.033 * * *$ & $0.042 * * *$ & $0.043 * * *$ \\
\hline & $(0.007)$ & $(0.007)$ & $(0.006)$ & $(0.005)$ & $(0.006)$ & $(0.006)$ \\
\hline \multirow[t]{2}{*}{ Mother Education } & 0.007 & $0.023 * *$ & $0.021 * *$ & 0.006 & $0.021 * *$ & $0.017 * *$ \\
\hline & $(0.011)$ & $(0.011)$ & $(0.009)$ & $(0.008)$ & $(0.009)$ & $(0.008)$ \\
\hline \multirow[t]{2}{*}{ Father education } & $0.020 * *$ & $0.022 * *$ & -0.003 & -0.002 & 0.008 & $0.011^{*}$ \\
\hline & $(0.008)$ & $(0.009)$ & $(0.006)$ & $(0.006)$ & $(0.006)$ & $(0.006)$ \\
\hline \multirow[t]{2}{*}{ Mother age } & $-0.049 * * *$ & $-0.068 * * *$ & -0.008 & -0.001 & $-0.036^{* * *}$ & $-0.044 * * *$ \\
\hline & $(0.007)$ & $(0.007)$ & $(0.005)$ & $(0.005)$ & $(0.005)$ & $(0.005)$ \\
\hline \multirow[t]{2}{*}{ Father age } & 0.001 & -0.003 & -0.002 & -0.002 & -0.001 & $-0.004 *$ \\
\hline & $(0.003)$ & $(0.003)$ & $(0.002)$ & $(0.002)$ & $(0.002)$ & $(0.002)$ \\
\hline \multirow[t]{2}{*}{ \# living children } & 0.008 & $0.046 * *$ & 0.016 & 0.007 & 0.014 & $0.032 * *$ \\
\hline & $(0.020)$ & $(0.019)$ & $(0.013)$ & $(0.014)$ & $(0.015)$ & $(0.013)$ \\
\hline \multirow[t]{2}{*}{ Household size } & 0.021 & -0.003 & -0.005 & 0.010 & 0.012 & 0.006 \\
\hline & $(0.015)$ & $(0.014)$ & $(0.011)$ & $(0.011)$ & $(0.012)$ & $(0.011)$ \\
\hline \multirow[t]{2}{*}{ Head Female } & -0.062 & -0.040 & -0.071 & $-0.180 * * *$ & -0.064 & $-0.155^{* * *}$ \\
\hline & $(0.075)$ & $(0.075)$ & $(0.056)$ & $(0.053)$ & $(0.054)$ & $(0.058)$ \\
\hline \multirow[t]{2}{*}{ Home appliances } & 0.024 & 0.054 & 0.010 & 0.049 & 0.009 & 0.071 \\
\hline & $(0.121)$ & $(0.114)$ & $(0.089)$ & $(0.088)$ & $(0.094)$ & $(0.092)$ \\
\hline \multirow[t]{2}{*}{ Piped water } & -0.014 & -0.069 & -0.097 & -0.063 & -0.068 & -0.082 \\
\hline & $(0.075)$ & $(0.074)$ & $(0.059)$ & $(0.054)$ & $(0.058)$ & $(0.058)$ \\
\hline \multirow[t]{2}{*}{ Well water } & 0.018 & -0.104 & -0.036 & -0.043 & -0.004 & $-0.083 *$ \\
\hline & $(0.065)$ & $(0.063)$ & $(0.047)$ & $(0.046)$ & $(0.048)$ & $(0.047)$ \\
\hline \multirow[t]{2}{*}{ Milk consumption } & $0.317 * * *$ & $0.172 * *$ & -0.053 & -0.014 & $0.131 * * *$ & 0.083 \\
\hline & $(0.069)$ & $(0.068)$ & $(0.049)$ & $(0.052)$ & $(0.048)$ & $(0.052)$ \\
\hline
\end{tabular}




\section{Macrothink}

Research in Applied Economics

ISSN 1948-5433

2021, Vol. 13, No. 3

\begin{tabular}{|c|c|c|c|c|c|c|}
\hline Meat consumption & $\begin{array}{l}0.159 \\
(0.145)\end{array}$ & $\begin{array}{l}-0.012 \\
(0.159)\end{array}$ & $\begin{array}{l}0.067 \\
(0.109)\end{array}$ & $\begin{array}{l}0.052 \\
(0.129)\end{array}$ & $\begin{array}{l}0.146 \\
(0.120)\end{array}$ & $\begin{array}{l}0.046 \\
(0.138)\end{array}$ \\
\hline Orthodox religion & $\begin{array}{l}-0.083 \\
(0.067)\end{array}$ & $\begin{array}{l}-0.040 \\
(0.068)\end{array}$ & $\begin{array}{l}0.163 * * * \\
(0.051)\end{array}$ & $\begin{array}{l}0.175^{* * *} \\
(0.053)\end{array}$ & $\begin{array}{l}0.063 \\
(0.052)\end{array}$ & $\begin{array}{l}0.104 * * \\
(0.051)\end{array}$ \\
\hline Protestant religion & $\begin{array}{l}0.013 \\
(0.075)\end{array}$ & $\begin{array}{l}0.143 * * \\
(0.072)\end{array}$ & $\begin{array}{l}0.251 * * * \\
(0.053)\end{array}$ & $\begin{array}{l}0.151 * * * \\
(0.051)\end{array}$ & $\begin{array}{l}0.182 * * * \\
(0.057)\end{array}$ & $\begin{array}{l}0.203 * * * \\
(0.053)\end{array}$ \\
\hline Ideal \# Girls & Yes & Yes & Yes & Yes & Yes & Yes \\
\hline Constant & $\begin{array}{l}-0.008 \\
(0.199)\end{array}$ & $\begin{array}{l}0.158 \\
(0.179)\end{array}$ & $\begin{array}{l}-0.972 * * * \\
(0.139)\end{array}$ & $\begin{array}{l}-0.728 * * * \\
(0.134)\end{array}$ & $\begin{array}{l}-0.738^{* * *} \\
(0.142)\end{array}$ & $\begin{array}{l}-0.459 * * * \\
(0.138)\end{array}$ \\
\hline Endowment diff & \multicolumn{2}{|c|}{$-0.010^{*}$} & \multicolumn{2}{|c|}{-0.009} & \multicolumn{2}{|c|}{-0.142} \\
\hline Coefficient diff & \multicolumn{2}{|c|}{$-0.123 * * *$} & \multicolumn{2}{|c|}{$-0.098 * * *$} & \multicolumn{2}{|c|}{-0.091} \\
\hline $\mathrm{CE}$ & \multicolumn{2}{|c|}{-0.002} & \multicolumn{2}{|c|}{$0.011 *$} & \multicolumn{2}{|c|}{0.005} \\
\hline Observations & 4514 & 4323 & 4514 & 4323 & 4514 & 4323 \\
\hline Adj R2 & 0.06 & 0.04 & 0.20 & 0.23 & 0.13 & 0.17 \\
\hline
\end{tabular}

Standard errors in parentheses, clustered at household level "* $\mathrm{p}<0.1,{ }^{*} \mathrm{p}<0.05, * * * \mathrm{p}<0.01$ " 
Table 2. Quantile Decomposition of Stunting for Boys. Effects of Individual Regressors

Recentered Influence Function (RIF)

\begin{tabular}{|c|c|c|c|c|c|c|c|c|c|}
\hline & q10 & $\mathrm{q} 20$ & $\mathrm{q} 30$ & $\mathrm{q} 40$ & q50 & q60 & q70 & $\mathrm{q} 80$ & q90 \\
\hline \multirow[t]{2}{*}{ D Rural } & -0.14 & -0.19 & -0.20 & -0.18 & $-0.22^{* *}$ & -0.14 & -0.11 & -0.15 & -0.25 \\
\hline & -0.18 & -0.16 & -0.12 & -0.12 & -0.10 & -0.11 & -0.16 & -0.13 & -0.17 \\
\hline \multirow[t]{2}{*}{ Drought } & -0.24 & $-0.33^{*}$ & $-0.36^{*}$ & -0.20 & $-0.28^{* *}$ & $-0.37^{* *}$ & $-0.38^{* *}$ & $-0.42^{* *}$ & $-0.67^{* *}$ \\
\hline & -0.17 & -0.17 & -0.19 & -0.16 & -0.11 & -0.15 & -0.18 & -0.19 & -0.27 \\
\hline \multirow[t]{2}{*}{$\mathrm{R}^{*} \mathrm{D}$} & 0.26 & 0.30 & 0.21 & 0.00 & 0.00 & 0.01 & -0.07 & -0.18 & -0.05 \\
\hline & -0.20 & -0.19 & -0.20 & -0.18 & -0.14 & -0.18 & -0.21 & -0.18 & -0.28 \\
\hline \multicolumn{10}{|l|}{ Age } \\
\hline \multirow[t]{2}{*}{$1-2$} & $-1.24^{* * *}$ & $-1.50^{* * *}$ & $-1.53^{* * *}$ & $-1.63^{* * *}$ & $-1.55^{* * *}$ & $-1.50^{* * *}$ & $-1.48^{* * *}$ & $-1.43^{* * *}$ & $-1.56^{* * *}$ \\
\hline & -0.13 & -0.13 & -0.07 & -0.10 & -0.08 & -0.09 & -0.09 & -0.11 & -0.14 \\
\hline \multirow[t]{2}{*}{$2-3$} & $-1.68^{* * *}$ & $-1.88^{* * *}$ & $-1.79^{* * *}$ & $-1.77^{* * *}$ & $-1.79^{* * *}$ & $-1.78^{* * *}$ & $-1.84^{* * *}$ & $-1.86^{* * *}$ & $-2.02^{* * *}$ \\
\hline & -0.16 & -0.12 & -0.09 & -0.09 & -0.10 & -0.09 & -0.07 & -0.10 & -0.11 \\
\hline \multirow[t]{2}{*}{$3-4$} & $-1.35^{* * *}$ & $-1.58^{* * *}$ & $-1.62^{* * *}$ & $-1.66^{* * *}$ & $-1.60^{* * *}$ & $-1.66^{* * *}$ & $-1.74^{* * *}$ & $-1.78^{* * *}$ & $-1.95^{* * *}$ \\
\hline & -0.10 & -0.07 & -0.07 & -0.08 & -0.09 & -0.08 & -0.09 & -0.11 & -0.13 \\
\hline \multirow[t]{2}{*}{$4-5$} & $-1.02^{* * *}$ & $-1.33^{* * *}$ & $-1.37^{* * *}$ & $-1.40^{* * *}$ & $-1.46^{* * *}$ & $-1.53^{* * *}$ & $-1.64^{* * *}$ & $-1.73^{* * *}$ & $-1.93^{* * *}$ \\
\hline & -0.09 & -0.11 & -0.08 & -0.10 & -0.10 & -0.09 & -0.09 & -0.11 & -0.15 \\
\hline \multirow[t]{2}{*}{ Wealth } & $0.05^{* * *}$ & $0.05^{* * *}$ & $0.04^{* * *}$ & $0.04^{* * *}$ & $0.03^{* * *}$ & $0.03^{* * *}$ & $0.03^{* * *}$ & $0.02^{* * *}$ & 0.02 \\
\hline & -0.01 & 0.00 & -0.01 & -0.01 & 0.00 & 0.00 & -0.01 & -0.01 & -0.01 \\
\hline \multirow[t]{2}{*}{ Education } & $0.03^{* * *}$ & $0.03^{* * *}$ & $0.03^{* * *}$ & $0.02^{* *}$ & $0.02^{* *}$ & $0.02^{* * *}$ & $0.02^{* *}$ & 0.02 & 0.01 \\
\hline & -0.01 & -0.01 & -0.01 & -0.01 & -0.01 & -0.01 & -0.01 & -0.01 & -0.01 \\
\hline \multicolumn{2}{|c|}{ Head Female-0.03 } & -0.03 & -0.03 & -0.07 & -0.03 & -0.10 & -0.08 & -0.03 & $0.29^{*}$ \\
\hline & -0.11 & -0.08 & -0.08 & -0.07 & -0.08 & -0.08 & -0.07 & -0.08 & -0.16 \\
\hline \multirow[t]{2}{*}{ Pipedwater } & -0.05 & 0.00 & -0.06 & -0.07 & 0.00 & -0.04 & 0.05 & -0.03 & 0.12 \\
\hline & -0.10 & -0.09 & -0.06 & -0.06 & -0.05 & -0.05 & -0.07 & -0.08 & -0.11 \\
\hline \multirow[t]{2}{*}{ Milk } & 0.19 & $0.25^{* *}$ & $0.25^{* * *}$ & $0.34^{* * *}$ & $0.37^{* * *}$ & $0.33^{* * *}$ & $0.39^{* * *}$ & $0.37^{* * *}$ & $0.32^{* * *}$ \\
\hline & -0.13 & -0.10 & -0.07 & -0.09 & -0.09 & -0.07 & -0.10 & -0.12 & -0.10 \\
\hline \multirow[t]{2}{*}{ Meat } & 0.04 & 0.19 & 0.03 & 0.02 & 0.15 & 0.08 & -0.03 & 0.04 & 0.11 \\
\hline & -0.37 & -0.20 & -0.18 & -0.23 & -0.18 & -0.16 & -0.13 & -0.23 & -0.27 \\
\hline Other & Yes & Yes & Yes & Yes & Yes & Yes & Yes & Yes & Yes \\
\hline \multicolumn{10}{|l|}{ Controls } \\
\hline \multirow[t]{2}{*}{ _cons } & -0.15 & -0.18 & -0.10 & -0.12 & -0.11 & -0.13 & -0.15 & -0.12 & -0.21 \\
\hline & -0.14 & -0.19 & -0.20 & -0.18 & $-0.22^{* *}$ & -0.14 & -0.11 & -0.15 & -0.25 \\
\hline
\end{tabular}

Standard errors in parentheses, clustered at household level "* $\mathrm{p}<0.1, * * \mathrm{p}<0.05, * * * \mathrm{p}<0.01$ ” 
Table 3. Quantile Decomposition of Stunting for Girls. Effects of Individual Regressors Estimated via Recentered Influence Function

\begin{tabular}{|c|c|c|c|c|c|c|c|c|c|}
\hline & $\mathrm{q} 10$ & $\mathrm{q} 20$ & $\mathrm{q} 30$ & $\mathrm{q} 40$ & $\mathrm{q} 50$ & $\mathrm{q} 60$ & $\mathrm{q} 70$ & $\mathrm{q} 80$ & q90 \\
\hline \multirow[t]{2}{*}{ D rural } & 0.29 & 0.12 & -0.11 & -0.02 & 0.05 & 0.02 & 0.08 & 0.10 & 0.17 \\
\hline & -0.30 & -0.18 & -0.12 & -0.11 & -0.13 & -0.15 & -0.13 & -0.16 & -0.16 \\
\hline \multirow[t]{2}{*}{ Drought } & 0.15 & -0.21 & $-0.34^{* * *}$ & $-0.22^{*}$ & -0.17 & $-0.19^{*}$ & -0.16 & -0.20 & -0.25 \\
\hline & -0.22 & -0.17 & -0.13 & -0.12 & -0.14 & -0.10 & -0.14 & -0.18 & -0.26 \\
\hline \multirow{2}{*}{$\mathrm{R} * \mathrm{D}$} & -0.13 & 0.18 & $0.24^{*}$ & 0.02 & -0.09 & -0.12 & -0.22 & $-0.36^{*}$ & -0.36 \\
\hline & -0.20 & -0.19 & -0.14 & -0.13 & -0.13 & -0.10 & -0.15 & -0.19 & -0.27 \\
\hline \multicolumn{10}{|l|}{ Age } \\
\hline \multirow[t]{2}{*}{ Age 1-2 } & $-1.28^{* * *}$ & $-1.29^{* * *}$ & $-1.35^{* * *}$ & $-1.35^{* * *}$ & $-1.36^{* * *}$ & $-1.40^{* * *}$ & $-1.47^{* * *}$ & $-1.45^{* * *}$ & $-1.42^{* * *}$ \\
\hline & -0.15 & -0.09 & -0.10 & -0.08 & -0.08 & -0.06 & -0.10 & -0.10 & -0.12 \\
\hline \multirow[t]{2}{*}{ Age 2-3 } & $-1.81^{* * *}$ & $-1.84^{* * *}$ & $-1.86^{* * *}$ & $-1.86^{* * *}$ & $-1.90^{* * *}$ & $-1.88^{* * *}$ & $-1.96^{* * *}$ & $-1.94^{* * *}$ & $-2.02^{* * *}$ \\
\hline & -0.12 & -0.11 & -0.08 & -0.08 & -0.08 & -0.08 & -0.12 & -0.10 & -0.20 \\
\hline \multirow[t]{2}{*}{ Age 3-4 } & $-1.72^{* * *}$ & $-1.68^{* * *}$ & $-1.74^{* * *}$ & $-1.75^{* * *}$ & $-1.77^{* * *}$ & $-1.76^{* * *}$ & $-1.88^{* * *}$ & $-1.88^{* * *}$ & $-1.96^{* * *}$ \\
\hline & -0.11 & -0.09 & -0.08 & -0.09 & -0.12 & -0.10 & -0.09 & -0.11 & -0.14 \\
\hline \multirow[t]{2}{*}{ Age 4-5 } & $-1.47^{* * *}$ & $-1.42^{* * *}$ & $-1.47^{* * *}$ & $-1.52^{* * *}$ & $-1.57^{* * *}$ & $-1.62^{* * *}$ & $-1.71^{* * *}$ & $-1.80^{* * *}$ & $-1.94^{* * *}$ \\
\hline & -0.13 & -0.05 & -0.06 & -0.05 & -0.06 & -0.08 & -0.08 & -0.11 & -0.16 \\
\hline \multirow[t]{2}{*}{ Wealth } & $0.05^{* * *}$ & $0.06^{* * *}$ & $0.04^{* * *}$ & $0.04^{* * *}$ & $0.03^{* * *}$ & $0.03^{* * *}$ & $0.03^{* * *}$ & $0.03^{* * *}$ & $0.02^{* * *}$ \\
\hline & -0.01 & -0.01 & -0.01 & -0.01 & -0.01 & -0.01 & -0.01 & -0.01 & -0.01 \\
\hline \multirow[t]{2}{*}{ Education } & $0.04^{* * *}$ & $0.03^{* * *}$ & $0.03^{* * *}$ & $0.03^{* * *}$ & $0.03^{* * *}$ & $0.03^{* * *}$ & $0.03^{* * *}$ & $0.02^{* *}$ & $0.04^{* * *}$ \\
\hline & -0.01 & -0.01 & -0.01 & -0.01 & -0.01 & -0.01 & -0.01 & -0.01 & -0.01 \\
\hline \multirow[t]{2}{*}{ Head Female } & 0.07 & -0.01 & -0.01 & -0.01 & -0.06 & 0.01 & -0.05 & -0.08 & -0.11 \\
\hline & -0.11 & -0.10 & -0.06 & -0.06 & -0.07 & -0.08 & -0.08 & -0.09 & -0.12 \\
\hline \multirow[t]{2}{*}{ Pipedwater } & 0.07 & -0.11 & 0.00 & -0.06 & 0.00 & 0.01 & -0.01 & -0.06 & -0.09 \\
\hline & -0.12 & -0.10 & -0.08 & -0.10 & -0.10 & -0.08 & -0.07 & -0.11 & -0.13 \\
\hline \multirow[t]{2}{*}{ Milk } & 0.13 & $0.18^{*}$ & 0.16 & $0.21^{* *}$ & $0.21^{* * *}$ & $0.15^{* *}$ & 0.13 & $0.23^{* *}$ & $0.20^{*}$ \\
\hline & -0.12 & -0.11 & -0.10 & -0.08 & -0.07 & -0.08 & -0.09 & -0.09 & -0.10 \\
\hline \multirow[t]{2}{*}{ meat } & 0.30 & $0.297^{*}$ & 0.04 & -0.05 & -0.18 & -0.14 & -0.20 & -0.18 & -0.29 \\
\hline & -0.27 & -0.16 & -0.08 & -0.11 & -0.13 & -0.16 & -0.20 & -0.27 & -0.22 \\
\hline Other & yes & yes & yes & yes & yes & yes & yes & yes & yes \\
\hline \multirow{2}{*}{ _cons } & $-2.52^{* * *}$ & $-1.55^{* * *}$ & $-0.89^{* * *}$ & $-0.58^{* * *}$ & $-0.26^{*}$ & 0.14 & $0.57^{* * *}$ & $1.14^{* * *}$ & $1.83^{* * *}$ \\
\hline & -0.24 & -0.18 & -0.15 & -0.13 & -0.14 & -0.13 & -0.12 & -0.15 & -0.18 \\
\hline
\end{tabular}

Standard errors in parentheses, clustered at household level " $* \mathrm{p}<0.1, * * \mathrm{p}<0.05, * * * \mathrm{p}<0.01$ ”

\section{Copyright Disclaimer}

Copyright for this article is retained by the author(s), with first publication rights granted to the journal.

This is an open-access article distributed under the terms and conditions of the Creative Commons Attribution license (http://creativecommons.org/licenses/by/3.0/). 